\title{
Laterality and visual persistence: Support for Di Lollo's model of hemispheric symmetry
}

\author{
GERALD M. LONG \\ Villanova University, Villanova, Pennsylvania
}

\begin{abstract}
An experiment that examines Di Lollo's claim (1981) for cortical symmetry of visible persistence effects is reported. In the present work, visible persistence is compared across the two visual fields on two types of currently popular persistence tasks and over two levels of target duration and target complexity. Although significant duration and complexity effects are obtained, no evidence for differential persistence in the hemifields is found for any set of stimulus conditions on either of the persistence tasks.
\end{abstract}

In the last few years, there has been some debate over the issue of laterality and visual persistence. Although early studies had reported evidence for asymmetrical persistence effects, these studies had often been of a contradictory nature. For example, whereas Erwin and Nebes (1976) reported greater persistence for stimuli presented to the left visual field (right hemisphere), Polzella, DaPolita, and Hinsman (1977) reported greater persistence for stimuli presented to the right visual field (left hemisphere). Cohen (1976) obtained evidence for a left field superiority on a partial-report task, but Marzi, DiStefano, Tassinari, and Crea (1979) reported no asymmetry on the same kind of persistence task over a range of stimulus conditions. In a recent attempt to reconcile these apparent contradictions, Di Lollo (1981) focused on the nature of the persistence tasks involved and proposed that those studies that obtained asymmetrical performance across the visual fields tended to employ tasks in which higher processes were involved. These higher processes, in turn, determined the particular nature (and direction) of the obtained asymmetry. Specifically, he argued that visible persistence per se is produced by very early stages of information processing and that "early stages of information processing are handled similarly and with equal efficiency by both hemispheres"' (p. 25).

In support of this proposal, Di Lollo (1981) found no evidence for laterality in his own work with a popular persistence task (Di Lollo, 1980; Di Lollo \& Bourassa, 1983; Hogben \& Di Lollo, 1974). He contended that this task, which requires the perceived simultaneity of 15 successively presented dots in a $4 \times 4$ array, necessitates "an enduring visible representation" of each stimulus dot (p. 24). This visible persistence is presumed to involve early sensory coding alone-without significant contri-

The research described here was supported in part by National Eye Institute Grant 1 RO1 EYO4485-01A1. I wish to thank Brian Lyman for his invaluable aid in collecting and analyzing the data. Reprint requests should be sent to Gerald M. Long, Department of Psychology, Villanova University, Villanova, PA 19805. bution from the higher processes hypothesized to be involved on other tasks.

In a brief comment on Di Lollo's (1981) study, a colleague and I (Wurst \& Long, 1983) raised some issues regarding the likely generality of his conclusions. Our concerns rested in two areas: (1) the limited range of stimulus conditions examined by Di Lollo and (2) the single persistence task he employed. Concerning the first point, impressive work by Sergent (1982a, 1982b, 1982c, 1983) has recently demonstrated the extreme sensitivity of laterality effects in general to variations in such stimulus conditions as duration, luminance, retinal location, and more. Concerning the second point, there is rather strong evidence that different persistence tasks may be assessing very different processes in the visual system (e.g., Wilson, 1983). This, in turn, raises the possibility that other persistence tasks may exhibit laterality effects even if they too rely on early processing stages. Given these two broad areas of reservation, we suggested that Di Lollo's conclusion from the null effect in his study was premature. The null effect is a weak starting point for a general claim: "But absence of evidence is not evidence of absence", (Sagan, 1977, p. 7).

In his rejoinder to these comments, Di Lollo (1983) largely emphasized particular distinctions between visible and nonvisible (or schematic) persistence and proposed definitional confusions (by us) between Type I and Type II persistence. These will not be repeated or rebutted here. Suffice it to say that Di Lollo and we have strong theoretical differences about the nature and locus of visual persistence effects. Rather, the present note describes a more empirical approach to the issue of laterality and persistence. Very simply, what if different stimulus conditions and different types of persistence tasks were used? Would the symmetry in results across the hemispheres reported by Di Lollo still obtain? These questions arise from largely atheoretical considerations concerning laterality and persistence, for it does not seem to me that there are specific, clear-cut predictions for either the symmetry or asymmetry of visual persistence.

In this work, two frequently used tasks from the per- 
sistence literature were employed to assess what are commonly termed Type I and Type II persistence. For the present, I can sidestep the issue of whether these two tasks assess different processes (Sakitt \& Long, 1979) or different aspects of a single process (Di Lollo, 1984). On the Type I persistence task, the observer adjusts (through a double staircase procedure) a probe stimulus $(1000-\mathrm{Hz}$, 20 -msec tone) so that it coincides in time with the offset of the target stimulus. This procedure was termed the "judgment of synchrony" task by Coltheart (1980). On the Type II persistence task, the observer adjusts the probe stimulus so that all visible trace of the fading target image has disappeared before the probe occurs. I conceptualize the two instructions as "probe-to-offset" and "probe-to-persistence," respectively; and observers have little difficulty in adopting either instruction (e.g., Long \& McCarthy, 1982; Sakitt \& Long, 1979).

\section{METHOD}

\section{Subject}

Thirty-four right-handed male volunteers participated in partial fulfillment of a course requirement in general psychology at Villanova University. Each subject participated individually in a single experimental session lasting approximately $45 \mathrm{~min}$.

\section{Apparatus, Stimuli, and Procedure}

All stimuli were presented in a three-channel Scientific Prototype tachistoscope (Model N/1000). With regard to the previously voiced concerns about the importance of stimulus conditions in this type of work, target duration was varied between 40 and $120 \mathrm{msec}$, and target complexity was varied between "simple" and "complex". The latter dimension involved two black targets of equal area $\left(620.25 \mathrm{~mm}^{2}\right)$ on a $17 \mathrm{~cd} / \mathrm{m}^{2}$ white field, but the targets differed greatly in perimeter. This served to alter the operationally defined complexity (Perimeter ${ }^{2} /$ Area) suggested in many studies (see Hochberg, 1972). Background luminance was held constant at $3.4 \mathrm{~cd} / \mathrm{m}^{2}$. And finally, the targets appeared in either the left or right visual field approximately $2^{\circ}$ from fixation. The eight stimulus conditions (two durations $\times$ two complexities $\times$ two fields) were presented twice in a random sequence to each of 17 right-handed male observers in the Type I task and to each of 17 (different) right-handed male observers in the Type II task.

Two frequently used tasks from the persistence literature were employed to assess what are commonly termed Type I and Type II persistence. On the Type I persistence task, the observer adjusted (through a double staircase procedure) a probe stimulus $(1000-\mathrm{Hz}, 20-\mathrm{msec}$ tone) so that it coincided in time with the offset of the target stimulus. On the Type II persistence task, the observer adjusted the probe stimulus so that all visible trace of the fading target image had disappeared before the probe occurred.

\section{RESULTS AND DISCUSSION}

The mean results for the two groups of observers are presented in Figure 1. The upper portion of Figure 1 shows the results from the Type I condition. Highly significant main effects of duration $[\mathrm{F}(1,16)=129.12, \mathrm{p}<$ $.0001]$ and complexity $[\mathrm{F}(1,16)=66.77, \mathrm{p}<.0001]$ are evident. The inverse effect of duration has been reported in many studies using similar tasks (e.g., Bowen, Pola, \& Matin, 1974; Efron, 1970; Long \& McCarthy, 1982). The strong inverse effect of complexity on Type I persistence is interesting and deserves additional study but will not

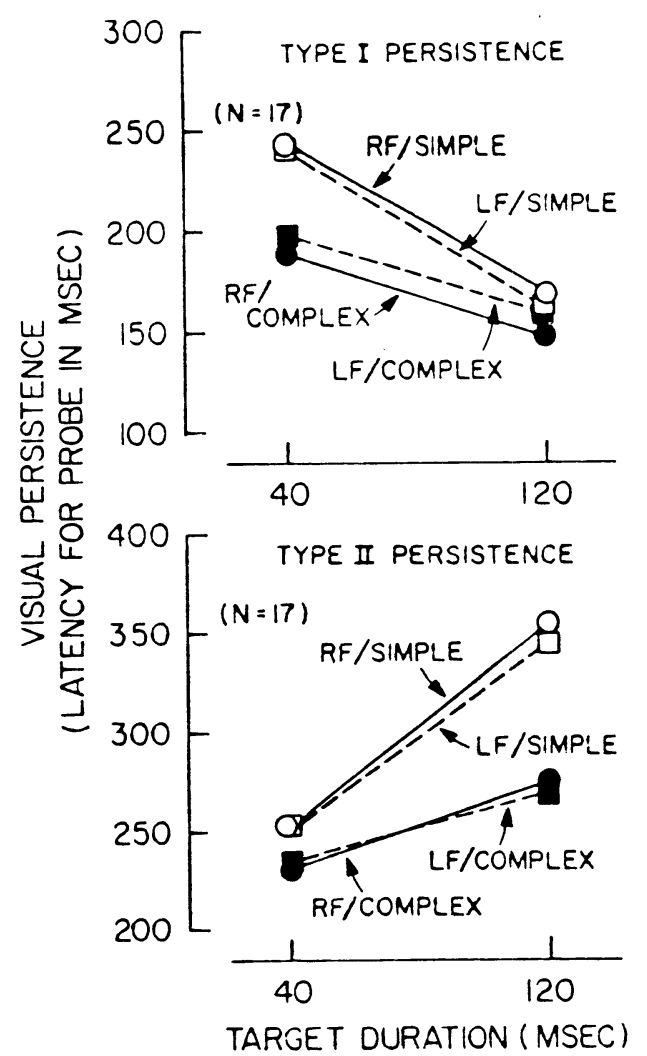

Figure 1. Mean persistence estimates as a function of target duration for the Type 1 condition (top) and Type II condition (bottom). Targets were "simple" or "complex" and were presented to either the left visual field (LF) or right visual field (RF).

be dealt with here. The duration $\times$ complexity interaction is also significant $[\mathrm{F}(1,16)=7.70, \mathrm{p}<.05]$. Particularly germane to the present discussion, however, is the effect of visual field $(\mathrm{F}<1.0)$. Consistent with $\mathrm{Di}$ Lollo's arguments and the results from his persistence task, there is no evidence for asymmetry in persistence on this task.

The lower portion of Figure 1 presents the mean results from the Type II condition. Note the consistently longer persistence estimates in the lower portion of Figure 1 than in the upper portion $[F(1,32)=21.38, p<.0001]$. This replicates previous work comparing performance on the two tasks (e.g., Sakitt \& Long, 1979). Also in contrast to the results with the Type I task, a highly significant positive effect of target duration on the Type II task is evident $[\mathrm{F}(1,16)=53.37, \mathrm{p}<.0001]$. This is consistent with the results of previous work on the same persistence task (e.g., Long, 1984). A highly significant inverse effect of complexity is also present for the Type II persistence $[F(1,16)=48.17, p<.001]$; and this finding replicates a very recent study of complexity effects and persistence (Long \& Wurst, in press). The duration $\times$ complexity interaction is also significant $[F(1,16)=$ $21.15, \mathrm{p}<.001]$. Finally, again consistent with 
Di Lollo's proposal, there is no evidence for any effect of visual field $(F<1.0)$.

It is believed that the present results significantly broaden the generality of Di Lollo's conclusion concerning the hemispheric symmetry of visible persistence. It is realized that other stimulus conditions or persistence tasks may yet reveal lateralized functioning, but Di Lollo's proposal has now been tested on three different tasks and over a range of stimulus conditions, and no cause for reservation has been found. These combined results, then, are in complete agreement with his proposal that visible persistence involves very early stages in the visual system prior to those that reveal hemispheric specialization. Although great differences still exist between $\mathrm{Di}$ Lollo and myself concerning our views on the nature of persistence and the bases for the widely reported differences across popularly used persistence tasks, the current evidence is entirely consistent with Di Lollo's original claim for the hemispheric symmetry of the phenomena in question.

\section{REFERENCES}

Bowen, R. W., Pola, J., \& Matin, L. (1974). Visual persistence: Effects of flash luminance, duration and energy. Vision Research, 14, 295-303.

Cohen, G. (1976). Components of the laterality effect in letter recognition: Asymmetries in iconic storage. Quarterly Journal of Experimental Psychology, 28, 105-114.

Coltheart, M. (1980). Iconic memory and visible persistence. Perception \& Psychophysics, 27, 183-228.

Di Lollo, V. (1980). Temporal integration in visual memory. Journal of Experimental Psychology: General, 109, 75-97.

Di LolLo, V. (1981). Hemispheric symmetry in the duration of visible persistence. Perception \& Psychophysics, 29, 21-25.

Di LoLLo, V. (1983). On laterality of visual aftereffects: A rejoinder. Perception \& Psychophysics, 33, 599-603.

DI LoLLo, V. (1984). On the relationship between stimulus intensity and duration of visible persistence. Journal of Experimental Psychology: Human Perception and Performance, 10, 144-151.

Di Lollo, V., \& Bourassa, C. M. (1983). Temporal integration following intensification of long-lasting visual displays. Vision Research, 23, 677-687.
EFron, R. (1970). Effect of stimulus duration on perceptual onset and offset latencies. Perception \& Psychophysics, 8, 231-234.

ERWIN, D. C., \& NeBES, R. D. (1976). Right hemispheric involvement in the functional properties of visual persistence. Paper presented at the Annual Meeting of the Eastern Psychological Association, New York City, April 21-24.

HochBerg, J. (1972). Perception I: Color and shape. In J. W. Kling \& L. A. Riggs (Eds.), Experimental psychology: Vol. 1. Sensation and perception. New York: Holt, Rinehart \& Winston.

HogBen, J. H., \& Di Lollo, V. (1974). Perceptual integration and perceptual segregation of brief visual stimuli. Vision Research, 14, 1059-1069.

LoNG, G. M. (1984). The pretreatment weighting technique. Journal of Experimental Psychology: Human Perception and Performance, 10, 140-143.

Long, G. M., \& MCCARThY, P. R. (1982). Target energy effects on Type 1 and Type 2 visual persistence. Bulletin of the Psychonomic Society, 19, 219-221.

LONG, G. M., \& WURST, S. A. (in press). Complexity effects on RT measures of visual persistence: Evidence for peripheral and central contributions. American Journal of Psychology.

Marzi, C. A., DiStefano, M., Tassinari, G., \& Crea, F. (1979). Iconic storage in the two hemispheres. Journal of Experimental Psychology: Human Perception and Performance, 5, 31-41.

Polzella, D. J., DaPolito, F., \& Hinsman, M. C. (1977). Cerebral asymmetry in time perception. Perception \& Psychophysics, 21, 187-192.

SAGAN, C. (1977). The dragons of Eden. New York: Ballantine Books.

SAKITT, B., \& LoNG, G. M. (1979). Cones determine subjective offset of a stimulus but rods determine total persistence. Vision Research, 19, 1439-1441.

SERGENT, J. (1982a). The cerebral balance of power: Confrontation or cooperation? Journal of Experimental Psychology: Human Perception and Performance, 8, 253-272.

SERGENT, J. (1982b). Influence of luminance on hemispheric processing. Bulletin of the Psychonomic Society, 20, 221-223.

SERGENT, J. (1982c). Theoretical and methodological consequences of variations in exposure duration in visual laterality studies. Perception \& Psychophysics, 31, 451-461.

SERGENT, J. (1983). Role of input in visual hemispheric asymmetries. Psychological Bulletin, 93, 481-512.

WILSON, J. T. L. (1983). Effects of stimulus luminance and duration on responses to onset and offset. Vision Research, 23, 1699-1710.

Wurst, S. A., \& LoNG, G. M. (1983). Laterality and visual persistence: Still a two-sided issue. Perception \& Psychophysics, 33, 595-598.

(Manuscript received for publication June 11, 1984.) 